\title{
Enseñanzas de la pandemia COVID-19. El reencuentro con la vulnerabilidad humana
}

\author{
Lessons from the COVID-19 pandemic. The re-encounter with \\ human vulnerability
}

\author{
M. de la Luz Casas Martínez \\ Centro Interdisciplinario de Bioética, Universidad Panamericana, Ciudad de México, México \\ Recibido el 1 de agosto de 2020; aceptado el 12 de agosto de 2020 \\ Disponible en Internet el 29 de septiembre de 2020
}

\section{Resumen}

La pandemia por el nuevo virus COVID-19 ha cimbrado a la humanidad por sus graves repercusiones en múltiples campos; no solamente en el de la salud, sino también en el económico, político y social. Desde la perspectiva ética, las crisis siempre llevan a la reflexión y en este caso ha sido evidente el reencuentro con un aspecto de la condición humana, la vulnerabilidad. La sociedad actual, hedonista y autónoma extrema, ha tratado de olvidarse de este aspecto, que la incomoda, pero que no puede ser ignorado bajo esta terrible crisis. La vulnerabilidad posee también un aspecto ético importante y por ello es necesario su reconocimiento y la voluntad de minimizar sus efectos. La presente reflexión se basa en el pensamiento de Martha Nussbaum,

Correo electrónico: mcasas@up.edu.mx 
quien proporciona una visión conjunta sobre la consideración de la vulnerabilidad y la justicia, enfoque muy necesario en la sociedad actual.

(C) 2020 Centros Culturales de México, A.C. Publicado por Masson Doyma México

S.A. Todos los derechos reservados.

Palabras clave: Bioética; Pandemia; COVID-19; Vulnerabilidad; Nussbaum

Abstract: The pandemic caused by the new virus COVID-19 has shaken humanity due to its serious repercussions in many fields, not only in health, but also at an economic, political, and social level. From the ethical perspective, crises always lead to reflection, and in this case, the re-encounter with an aspect of the human condition, vulnerability, has been evident. Today's extreme hedonistic and autonomous society has tried to forget about this aspect, which makes it uncomfortable, but which cannot be ignored with this terrible crisis. Vulnerability also has an important ethical aspect, and therefore its recognition and the will to minimise its effects is necessary. The present reflection is based on the thoughts of Martha Nussbaum, who provides a joint vision on the consideration of vulnerability and justice; a very necessary approach in today's society.

(C) 2020 Centros Culturales de México, A.C. Published by Masson Doyma México S.A. All rights reserved.

Key words: Bioethics; Pandemic; COVID-19; Vulnerability; Nussbaum

\section{Introducción}

La pandemia COVID-19 (SARS-CoV-2) ha tomado a la humanidad por sorpresa, por tratarse de un organismo nuevo, con alto grado de propagación y un manejo complejo de sus diferentes fases de historia natural de presentación, además del desabasto de los recursos médicos disponibles en todos los países, la falta de tratamiento específico y las múltiples repercusiones psicológicas, económicas y políticas.

Esta pandemia ha involucrado a todos, países ricos y pobres y geográficamente diferentes (WHO, 2020).

Si bien hay que reconocer los grandes daños que la pandemia ha ocasionado, no se deja de reflexionar sobre los aprendizajes que ella nos ha traído, no solamente desde la perspectiva material que incluiría desarrollar una infraestructura suficiente en el campo de la salud, una adecuada regulación y administración de los recursos económicos, capacidad para colaboración internacional expedita en investigación y 
estructura general de manejo epidemiológico, entre otros, sino que también en el campo ético ha dejado temas reflexivos de importancia para esta y las subsecuentes crisis de salud mundial.

La solidaridad, compasión, reciprocidad, justicia, honestidad de muchos individuos se ha mostrado en forma directa e indirecta a través de medios masivos de comunicación, pero a la vez también se han manifestado actitudes de egoísmo, deshonestidad, injusticia y mentira. Es evidente que las crisis sacan a la luz lo mejor y lo peor de la libertad humana.

Es verdad que son necesarias acciones preventivas, especialmente desde la perspectiva de asignación de recursos al campo de la salud e investigación, es verdad que se ha puesto de manifiesto la carencia de servicios, que aunque obligados por ley, en la práctica no fueron suficientes ni eficientes, como el caso del campo tanatológico y cuidados paliativos.

Pero, ante gran parte del pensamiento occidental, basado en una sociedad individualista, materialista, autonómica y autosuficiente, la pandemia nos recuerda un componente de nuestra naturaleza humana, que frecuentemente se trata de minimizar en la cultura actual: la vulnerabilidad.

La Real Academia Española (2020) define vulnerabilidad como «aquello que puede ser herido o recibir lesión, física o moralmente».

Es inevitable ante situaciones de crisis no reconocer la vulnerabilidad humana, pues frente a esta sociedad de poder la naturaleza nos lo recuerda no solamente en casos personales, como el dolor, la enfermedad y la muerte, sino también ante la impotencia frente a catástrofes naturales, como los terremotos, el cambio climático y las epidemias y pandemias, entre otros.

Ante el mar de actitudes y valores presentes en la actual pandemia es importante la reflexión de esta condición, pues ello nos permitirá mejores abordajes presentes y futuros, puesto que las acciones humanas son resultado de sus intereses y valores y todo ello repercute no solamente en forma personal, sino política y social.

La presente reflexión, en su mayoría, tiene bases en el pensamiento de Martha Nussbaum, ya que ella proporciona una visión conjunta sobre la consideración de 
la vulnerabilidad y la justicia, tan necesaria en las condiciones actualmente vividas por nuestra sociedad.

\section{Vulnerabilidad humana y pandemia}

La historia, el arte y la realidad nos enfrentan a la precariedad de la existencia humana.

Los acontecimientos que están más allá del control de una persona llevan merecida o inmerecidamente a posibles daños físicos o psicológicos que la someten a la inseguridad y pérdida de su calidad de vida, especialmente si se refieren a pérdidas consideradas valiosas en la escala personal de valores, afectando seriamente a sus emociones, como lo señala Nussbaum: «son respuestas a las áreas de vulnerabilidad, en las que registramos los perjuicios que sufrimos, que podríamos sufrir, o que por suerte no padecemos» (Nussbaum, 2006, p. 16).

La vulnerabilidad humana, especialmente ante el azar o el destino, es vivida en forma material, psicológica y espiritual por todo ser humano y puede amenazar su capacidad de decidir y actuar.

El ser vulnerables nos vuelve necesitados no únicamente de bienes materiales, como la salud y la economía, sino de vínculos humanos, como la amistad, el respeto, el amor, ya que solamente otro humano puede reconocer y comprender nuestras carencias y compartir y ayudar en nuestras necesidades.

La vulnerabilidad, por tanto, presenta un aspecto positivo, pues al ser compartida puede promover la relación humana de empatía, solidaridad y subsidiariedad; y al contrario, el desconocimiento de la vulnerabilidad por parte de aquellos que se presentan como invulnerables desde la perspectiva económica o del poder pueden cometer graves actos de deshumanización, pues no identifican como semejante la dignidad de los otros, aunque tarde o temprano llegarán a ellos las crisis vitales que por naturaleza se poseen y tendrán que reflexionar sobre ello.

Como se señaló anteriormente, la realidad nos muestra que todos los seres humanos, como criaturas, somos individuos frágiles, necesitados e incompletos, desvalidos ante males materiales y víctimas del mal moral ocasionado por otros, ya sea provocado o no intencionalmente. 
La existencia siempre está rodeada de riesgos, los cuales aprendemos a manejar desde la infancia, riesgos físicos, riesgos psicológicos y espirituales, fortaleciendo la inteligencia, desarrollando estrategias, mas nunca esto es suficiente, como nos lo muestra la situación crítica de esta pandemia.

Así, para minimizar los riesgos de la vulnerabilidad, primero hay que reconocerla y segundo, desarrollar estrategias protectoras.

Bajo los hechos de esta pandemia existieron muchas fallas al respecto, como fue el retraso en su reconocimiento, la falta de estudio a través de autopsias bajo protocolo y especialmente la deficiencia de los sistemas de salud para afrontarla (WHO, 2020).

Faltaron reconocimiento y estrategias protectoras, especialmente en países en desarrollo en donde en ocasiones ya se contaba con un servicio de salud deficiente y depauperado (World Health Organization,2020).

La pandemia ha mostrado a los gobiernos la reconsideración de la salud como uno de los bienes más importantes de su población, sin ella no hay economía, sociedad ni estabilidad. La pandemia ha mostrado que el gasto destinado a la salud es una inversión poderosa para los estados.

Cada persona se ha sentido vulnerable bajo esta catástrofe, aun manteniendo las medidas sanitarias propuestas por las autoridades sanitarias competentes, ya que tratándose de un nuevo virus no existen fármacos apropiados para su tratamiento ni vacuna específica preventiva, lo cual complicó las medidas iniciales propuestas desde China para su manejo.

Ante situaciones personales o ampliamente difundidas en medios masivos de comunicación se han suscitado emociones morales de acercamiento humano como la compasión, la empatía, la ayuda a conocidos y desconocidos.

Para Nussbaum, las emociones son la respuesta a la condición de vulnerabilidad. Este tipo de emociones provienen del reconocimiento del otro y de los límites de nuestra autosuficiencia frente a las circunstancias particulares de la vida, de darles significado humano.

Estas reacciones las hemos visto en la angustia ante la escasez de insumos de bienes indivisibles, como fue el caso de las unidades de cuidados intensivos y respiradores, el sostenimiento del confinamiento, la pérdida laboral, el límite económico 
de muchas familias, la falta de insumos para personal de salud, la imposibilidad de lograr servicio médico o psicológico en urgencias. Muchos actos humanitarios se han constatado, muchas personas e instituciones, a través de las personas que las conforman, se han manifestado ayudando en sus capacidades a aquellos más carentes.

Sin duda la compasión puede ser una forma inestimable de acrecentar la conciencia ética, como señala Nussbuam: «la persona siempre tendrá razones más sólidas para alentar el ejercicio de la imaginación compasiva que atraviesa las fronteras sociales y propende por la defensa de los derechos fundamentales» (Nussbaum, 2001, p. 130).

El sufrimiento reconocido del otro en forma empática nos hace semejantes, nos humaniza. Así se ha percibido en esta pandemia a través de los medios de comunicación; hay igualdad ante ella para todas las personas independientemente de su raza, color, país, cultura, estado económico o social; la vulnerabilidad, el dolor y la muerte son semejantes para todos, en forma real o hipotética, podemos identificarnos.

Las decisiones políticas no se plantean ni se realizan en el abstracto; las hacen las personas, sus valores y objetivos, y por ello la formación moral de cada individuo en este campo repercute en las políticas. Este punto ha sido también esencial en esta pandemia.

Nussbaum (2014) reflexiona precisamente sobre ello en su libro Emociones políticas, donde plantea el importante valor ético de las emociones y su influencia en la vida política de las actuales sociedades democráticas.

Desde finales de los años noventa, Nussbaum ha propuesto la idea de que existe un vínculo entre emociones, justicia social y vida moral. La autora señala que las capacidades humanas parten de la comprensión de las emociones que pueden motivar la compasión y el amor, que tienen una relevante, pero también de aquellas que obstaculizan las conquistas de la justicia, como el odio hacia personas o grupos ocasionado por emociones ligadas a estereotipos o creencias (Nussbaum, 2008).

Las emociones a menudo no tienen base racional o argumentativa sólida, pero su fuerza motiva muchas veces las acciones y por ello la necesidad de su comprensión.

En el caso de esta grave problemática de salud, la compasión puede servir de sostén a la idea de justicia formulada en el enfoque de las capacidades 
(Nussbaum, 2002). Sin embargo, esta emoción no es por ella misma una solución universal, teniendo en cuenta que las personas suelen sentirla de un modo restringido y desigual. Por consiguiente, nos señala la autora, dos de las preguntas que se nos plantean frente a las emociones que resultan relevantes para el ámbito de la política serían ¿cómo apoyar el concepto de la igualdad humana? Y ¿cómo educar las emociones respetando la libertad de expresión y el debate? (Nussbaum, 2012, p. 213).

Hemos podido observar numerosas expresiones emotivas a través de medios masivos de comunicación, no solamente en aquellos individuos en quienes las pérdidas han sido irreparables, sino también en manifestaciones comunitarias que se han hecho patentes aún en aislamiento por medio de videograbaciones distribuidas en medios masivos como Youtube, Whatsapp, streaming, televisión o medios escritos, como ha sido el caso de personas que desde su ventana se manifiestan en acciones compartidas de aliento y esperanza hacia el personal de salud o de la comunidad en general. Las emociones mueven personas y comunidades.

Aunque, como nos lo muestra la ética, las emociones no deberían ser el sustento principal de las acciones, sino un medio para la autorreflexión y la formación moral de un individuo.

Nussbaum entonces se dirige hacia el tratamiento de las emociones y su relación con el razonamiento ético como un medio para cultivar la ciudadanía democrática que se necesita en las actuales sociedades liberales (Nussbaum, 2008, 2012).

Los políticos, en la práctica, sí toman en cuenta las emociones, pues muchas personas no llegan a través de ellas al proceso de argumentación. Por tanto, un modo de influencia política es el peso de las emociones públicas, las cuales pueden constituir elementos valiosos en la aspiración a la justicia.

\section{Altruismo, compasión y pandemia}

Ante esta gran problemática mundial, el altruismo ha sido uno de los puntos más necesarios para enfrentarla, especialmente porque se trata de una tarea imposible de abordar sin el apoyo de la comunidad. El estado, el sistema de salud, efectivamente es esencial, pero también lo es que cada persona colabore en la disminución del contagio, que amenaza realmente la capacidad de atención de los pacientes, 
especialmente aquellos graves. Sin colaboración comunitaria, no es posible contener una transmisión viral efectiva. Nussbaum apunta:

Hoy tenemos la urgente necesidad de contar con una buena teoría explicativa de las emociones de los ciudadanos y las ciudadanas en una sociedad digna. Esta tarea exige una reflexión conceptual sobre las emociones, sobre cómo surgen y se despliegan, sobre cuál es su estructura y sobre cómo interactúan entre sí (Nussbaum, 2012, p. 120).

En La terapia del deseo Nussbaum (2003) reflexiona sobre la importancia de las emociones a partir de una revisión crítica de Aristóteles, los estoicos y los epicúreos y señala que un detonante importante sería la compasión. La compasión es una emoción que posee un potencial relevante para la reflexión ética, porque va asociada a la deliberación humana que compara el «buen vivir» con la carencia real de ella.

El concepto es también referido por Pinedo (2018), quien realiza una interesante aportación señalando que:

. . la compasión es una intuición moral que nos informa acerca del mejor modo de comportarse para contrarrestar, mediante la consideración, el respeto y la benevolencia, la extrema vulnerabilidad de las personas, una emoción vinculada con la búsqueda de la justicia y la acción moral, en donde se pone en juego la conciencia por medio de juicios, decisiones y compromisos que dan cuenta de los principios y fines que orientan a la persona, y que son capaces de humanizar la realidad al traducirse en obras para los demás.

Por esta razón, la compasión en el pensamiento de Nussbaum (1996) tiene un papel importante en la ética y en la ética jurídica. Compadecerse del sufrimiento ajeno, señala Nussbaum, si es una emoción genuina, deberá trascender hacia la vida pública.

Precisamente eso es lo esperado en estos momentos, que los actos individuales se conviertan no solamente en comunitarios aislados, sino en acciones gubernamentales acordes a las necesidades vividas y experimentadas por la población afectada, defendiendo la dignidad para defender la igual dignidad y valor de todos los seres humanos. 
Nussbaum expresa la necesidad de hacer frente al sufrimiento en todas sus formas, sin importar que la experiencia de dolor acontezca en vidas distantes y distintas al entorno más inmediato en que nos encontramos (Nussbaum, 2014).

La sociedad compasiva reflexiona y pide acción ante la detección de necesidades de los seres humanos, cercanos o no, en los que se detecta la injusticia, la vulnerabilidad y la falta de calidad de vida, como frecuentemente hemos presenciado en las múltiples y diversas manifestaciones en esta situación crítica, porque ya nos lo dice la ya citada autora: «uno de los peores aspectos de la privación es que despoja a la gente de sus aspiraciones y del sentido de la dignidad» (Nussbaum, 1997, p. 81).

La compasión ante la injusticia causa indignación, especialmente si se suscita por la falta de reconocimiento y empatía política que debería atenderlas.

Es ante la indiferencia política que se determina la exigencia social a las autoridades para que hagan su trabajo, promuevan la justicia y cumplan con su cometido de garantes de la dignidad humana.

La compasión se motiva ante aquellos vulnerables, sin defensa personal, padeciendo discriminación y crueldad y exige acciones, las cuales deben ascender desde el nivel personal al jurídico y social en forma expedita y eficiente.

La integración de la política a las acciones éticas es, sin duda, uno de los reclamos más frecuentes en la obra de Nussbaum, y esto implica incluir una perspectiva compasiva en el derecho, las leyes y las instituciones públicas, más allá de lo que se espera que todo gobierno haga mínimamente por suplir las necesidades básicas de todos los ciudadanos (Nussbaum, 2014).

Si reconocerse como humano es reconocer desde la filosofía que se es vulnerable, el concepto tiene actualmente un tamaño interdisciplinario; el derecho, las ciencias sociales, la economía y por supuesto la medicina y psicología lo reconocen, y ya que se reconoce, la racionalidad humana nos pide prevenirla o minimizarla en lo posible.

Si es cierto que todos somos vulnerables, no todos lo somos de la misma forma o grado. Existen diversos factores de riesgo, genéticos, conductuales personales, sociales y hasta históricos. 
En el caso de esta pandemia, la enfermedad física puede estar unida a trastornos psicológicos de angustia y ansiedad y también a crisis económica y social. Los factores de vulnerabilidad se combinan y son complejos.

Si bien la resignación es una forma personal de negarse a la lucha ante la creencia de lo inevitable, es también una forma de pérdida de dignidad que puede llevar poco a poco no solamente a la desesperanza, sino a la depresión profunda.

Pero, existen aquellos que no se rinden ante la adversidad o que cuentan con el apoyo de aquellos que practican la compasión y que los acompañan a superar sus factores vulnerables con un sentido de humanidad.

Como sugiere Nussbaum, «el gran papel de las emociones juegan en forma importante en la trayectoria de las vidas humanas...si nos olvidamos de las respuestas emotivas. . dejamos fuera gran parte de nuestra humanidad» (Nussbaum, 2004).

\section{Conclusiones}

Las crisis vitales promueven la reflexión humana.

Valores y la falta de ellos aparecen frente al dolor, la muerte y el sufrimiento.

Esta pandemia nos hace reflexionar en cómo afrontarla, esta y las futuras, en forma más eficiente y humanizada.

Por la misma característica de estos eventos, son necesarias las acciones personales y comunitarias, pero también las políticas para poder contar con los medios y medidas que apoyen las acciones reguladoras de los males que se presenten.

La reflexión en torno a la vulnerabilidad humana nos lleva a un campo poco apoyado por la educación informal de la sociedad actual, gran parte de ella situada en el egocentrismo, la autonomía irrestricta y el hedonismo.

Al reconocer la vulnerabilidad humana y social como parte de nuestra naturaleza se podrán realizar mejores estrategias. 
Hay que impulsar por tanto los valores personales y sociales, de tal forma que repercutan en la vida política de los países, a fin de llegar al respeto y dignidad que cada persona tiene.

La resignación no es una actitud humana aceptable, pues disminuye el reconocimiento de la dignidad de cada persona; es necesario el enfrentamiento inteligente de los diversos factores de vulnerabilidad.

Si bien el sufrimiento es vivencial y no puede ser completamente compartido por otro, sí existe una identificación aproximativa que nos acerca como humanos, que nos lleva del «yo» al «tu», a su ayuda y acompañamiento, que nos recuerda que la naturaleza humana también es benevolente y busca el bien y la justicia.

Los desastres naturales no pueden ser previstos ni evitados completamente, pero sin duda, la formación moral de las personas puede contener mecanismos de defensa apropiados y útiles ante ellos. Los valores morales aplicados son la base de nuestra humanidad y por ello la reflexión sobre ellos es una enseñanza importante de este grave momento histórico.

Es nuestro deber reconocer y disminuir el daño de la vulnerabilidad intrínseca de nuestra naturaleza. Sin duda, la formación ética y su detonante emotivo pueden desarrollar estrategias exigibles políticamente para obtener cambios significativos en las próximas emergencias.

La vulnerabilidad humana es real, intrínseca e imposible de evitar al cien por ciento, pero también es necesaria, pues detona grandes valores y acciones humanas que caracterizan a la especie como digna y responsable.

Esta pandemia también nos ha aportado muchas acciones y reflexiones positivas, que parten precisamente de lo que somos, una humanidad compasiva.

\section{Conflicto de intereses}

La autora declara no tener ningún conflicto de intereses.

\section{Referencias}

Nussbaum, M. (1996). Compassion: The Basic Social Emotion. Social Philosophy and Policy, 13(1), $27-58$. http://dx.doi.org/10.1017/s0265052500001515 
Nussbaum, M. (1997). Justicia poética. La imaginación literaria y la vida pública. Barcelona: Andrés Bello (Trad. C. Gardini).

Nussbaum, M. (2001). El cultivo de la humanidad. Una defensa clásica de la reforma en la educación liberal. Barcelona: Andrés Bello.

Nussbaum, M. (2002). Las mujeres y el desarrollo humano. El enfoque de las capacidades. Barcelona: Herder.

Nussbaum, M. (2003). La terapia del deseo. Teoría y práctica en la época helenística. Barcelona: Paidós (Trad. M. Candel),

Nussbaum, M. (2004). Cap. 1. Emotions and law. In Hiding from Humanity: Disgust, Shame, and the Law. Princeton: Princeton University Press.

Nussbaum, M. (2006). El ocultamiento de lo humano. Repugnancia, vergüenza y ley (Trad. G. Zadunaisky). Buenos Aires: Katz. 214 Universitas Philosophica, 36(73).

Nussbaum, M. (2008). Paisajes del pensamiento. La inteligencia de las emociones. Barcelona: Paidós (Trad. A. Maira).

Nussbaum, M. (2012). Crear capacidades: propuesta para el desarrollo humano. Barcelona: Paidós.

Nussbaum, M. (2014). Emociones políticas. ¿Por qué el amor es importante para la justicia? Barcelona: Paidós (Trad. A. Santos Mosquera).

Pinedo, I. (2018). De la benevolencia a la ciudadanía compasiva: La recuperación de conceptos claves para el cultivo de la democracia. Límite: Revista Interdisciplinaria de Filosofía y Psicología, 13(41), 29-45.

Real Academia Española. Diccionario de la lengua española, 23. a ed. [versión 23.3 en línea] [consultado 3 Ago 2020]. Disponible en: https://dle.rae.es/vulnerable?m=form

WHO (2020). Enfermedad por el Coronavirus (COVID-19) [consultado 10 Ago 2020]. Disponible en: https://www.paho.org/es/tag/enfermedad-por-coronavirus-covid-19

World Health Organization (2020). COVID-19 [consultado 10 Ago 2020]. Disponible en: https://www.who.int/es 